
\title{
28 Research Suare \\ Establishment of a Chronic Trypanosoma Equiperdum Infection Model in Mice
}

\section{Yusuke Tanaka}

Department of Veterinary Medicine, Obihiro University of Agriculture and Veterinary Medicine

\section{Keisuke Suganuma}

National Research Center for Protozoan Diseases, Obihiro University of Agriculture and Veterinary

Medicine

\section{Kenichi Watanabe}

Research Center for Global Agromedicine, Obihiro University of Agriculture and Veterinary Medicine Yoshiyasu Kobayashi ( $\sim$ kyoshi@obihiro.ac.jp )

Research Center for Global Agromedicine, Obihiro University of Agriculture and Veterinary Medicine

\section{Research Article}

Keywords: dourine, histopathology, Trypanosoma equiperdum, mouse model

Posted Date: December 18th, 2020

DOI: https://doi.org/10.21203/rs.3.rs-128721/v1

License: (1) (1) This work is licensed under a Creative Commons Attribution 4.0 International License. Read Full License 


\section{Abstract}

Dourine, caused by chronic infection with Trypanosoma equiperdum, is one of the African trypanosomiasis in equids. Since the pathogenesis of dourine has not yet been elucidated, experimental studies using mouse infection models are needed. However, mice cannot be infected with most $T$. equiperdum strains or rapidly develop parasitemia if infection is established and die within a few days. A sequential method of isolating parasites from dourine-affected horses and adapting them to in vitro cultures using soft agarose media was recently developed. Various $T$. equiperdum strains adapted to in vitro conditions have since been established using this technique. We used one of these strains, the $T$. equiperdum IVM-t2 strain. In the present study, we inoculated mice with the IVM-t2 strain and successfully produced a chronic infection model in mice. In the clinical examination, periodic parasitemia and skin plaques, which are characteristic clinical signs of dourine-affected horses, were observed. A histopathological examination revealed that some of the lesions observed in infected horses, such as vaginitis, trypanosomal sand, and peripheral neuritis, were reproduced in mice. This mouse model will be a valuable tool for pathological, immunological, and parasitological in vivo research, and will contribute to investigations on the mechanisms underlying the disease process and the host-protozoa relationship.

\section{Introduction}

Trypanosoma brucei rhodesiense, T. brucei gambiense, T. brucei brucei, T. evansi, and T. congolense are causative agents of African trypanosomiasis in humans and livestock ${ }^{1,2}$. Although mice are not natural hosts of these African trypanosomes, various multi-faceted infection models of the disease in mice have been established in the past decade. These mouse infection models have been utilized in pathological and immunological studies to elucidate the pathogenesis of trypanosomiasis ${ }^{3}$.

Dourine, one of the African trypanosomiasis in equids, is caused by chronic infection with $T$. equiperdum ${ }^{4-6}$. Infected horses manifest various clinical signs, such as edema of the external genitalia, skin plaques, and neurological signs ${ }^{5}$. Pathological examinations of infected horses revealed that these clinical signs are caused by inflammation and edema of the genital organs, dermatitis, and peripheral polyneuritis, respectively ${ }^{6-9}$. However, the pathogenesis of dourine remains largely unknown. Similar to other African trypanosomiasis, experimental studies using mouse infection models are needed to elucidate the mechanisms underlying the disease process and the host-protozoa relationship in dourine. However, mice are not infected with most $T$. equiperdum strains, or rapidly develop parasitemia if an infection is established and die within a few days ${ }^{8,10-12}$. Therefore, a chronic T. equiperdum infection model in mice has never been established.

Trypanosoma equiperdum strains used in previous studies on experimental infections were prepared by subculturing the blood of horses with parasitemia in mice ${ }^{8,11-13}$. Suganuma et al. recently established a method to isolate $T$. equiperdum from the genital mucosa of dourine-affected horses and adapt them to in vitro cultures using soft agarose media ${ }^{14}$. The usage of $T$. equiperdum strains adapted and grown 
under in vitro conditions provides a more stable and quantitative supply of these parasites for experimental studies. Using this technique, Suganuma et al. isolated some T. equiperdum strains from dourine-affected horses in Mongolia (unpublished data). One of the isolated strains from Mongolian horses, named the T. equiperdum IVM-t2 strain, was used in the present study.

Helper T cells play important roles in the control of immune responses. Two major subtypes of helper $\mathrm{T}$ cells, helper 1 (Th1) and helper $2 \mathrm{~T}$ (Th2) cells, have been identified ${ }^{15}$. The dominant subtype of helper $T$ cells is different in each inbred mouse strain. BALB/C and C57BI/6, both of which are the most commonly used mouse strains for experimental studies on African trypanosomes ${ }^{3}$, have been identified as Th2- and Th1-prone strains, respectively ${ }^{16-19}$. Previous studies on viral and bacterial diseases indicated differences in susceptibility to pathogens between these two mouse strains ${ }^{20,21}$. Furthermore, survival times and susceptibility markedly differed between BALB/c and C57BI/6 in experimental studies on African trypanosomiasis ${ }^{3}$.

It currently remains unknown whether $T$. equiperdum induces Th1-dominant or Th2-dominant immunity in vivo in horses and mice. Therefore, we inoculated BALB/C and C57BI/ 6 mice with the above mentioned strain of T. equiperdum, and successfully produced a chronic infection model in mice. The present study deals with the clinical and pathological features of these mice infected with the T. equiperdum IVM-t2 strain and compared species differences in these features.

\section{Results}

\section{Clinical examination}

Five out of 6 (83\%) BALB/c mice in the infected group (IG) survived throughout the experimental period, 60 days post infection (dpi). One BALB/c mouse in IG died during anesthesia for blood collection at 31 dpi. Three out of $6(50 \%)$ C57BI/ 6 mice in IG survived throughout the experimental period. Two mice died and 1 mouse was euthanized because of greatly reduced motility and depression at $10 \mathrm{dpi}$. Two out of the 3 surviving $\mathrm{C} 57 \mathrm{BI} / 6$ mice in IG developed redness and alopecia on the dorsal skin from 31 and $43 \mathrm{dpi}$, respectively, to euthanasia at $60 \mathrm{dpi}$ (Fig. 1). The first peak of parasitemia was detected at 10 and $8 \mathrm{dpi}$ in $\mathrm{BALB} / \mathrm{C}$ and $\mathrm{C} 57 \mathrm{BI} / 6$ mice in IG, respectively. Periodic parasitemia was then observed until $60 \mathrm{dpi}$ in IG of both mouse strains (Fig. 2). Mice in the control group (CG) in both mouse strains did not exhibit any clinical signs.

\section{Histopathological examination}

The degree of inflammation in each organ and tissue collected from IG mice was summarized in Table 1. Various degrees of vaginitis were observed in all mice in IG of both mouse strains. Mild (+) or moderate $(++)$ vaginitis was characterized by perivascular inflammation in the lamina propria and tunica muscularis. In severe (+++) vaginitis, inflammatory cells were diffusely observed at the vaginal lamina propria and tunica muscularis (Fig. 3a). Perineuritis of the sciatic nerve was noted in 6/6 BALB/c mice and 5/6 C57BI/6 mice in IG, and severe inflammation was more frequently detected in C57BI/6 mice in IG 
$(3 / 6)$ than in BALB/c mice in IG (1/6). Inflammation of the sciatic nerve was confined to the perineurium and surrounding connective tissues, while inflammatory cells were not found within nerve bundles (Fig. 3b). Mild axonal degeneration was also noted in the sciatic nerve of $2 \mathrm{BALB} / \mathrm{c}$ mice and $1 \mathrm{C} 57 \mathrm{BI} / 6$ mouse in IG (Fig. 3b). Edema and the diffuse infiltration of lymphocytes in the dermis and subcutaneous tissue were observed in dorsal skin lesions presenting alopecia and redness in $2 \mathrm{C} 57 \mathrm{BI} / 6$ mice in IG. The numbers of hair follicles and cutaneous glands were reduced (Fig. 3c). Although apparent skin lesions were not grossly observed in BALB/c mice in IG, the moderate infiltration of lymphocytes into the dermis and subcutaneous tissue of the dorsal skin was noted in 2 out of 5 mice. Hepatitis, characterized by the perivascular infiltration of lymphocytes, macrophages, and plasma cells, was detected in $3 / 6 \mathrm{BALB} / \mathrm{c}$ and $5 / 6 \mathrm{C} 57 \mathrm{BI} / 6$ mice in IG. Although hepatitis in BALB/c mice was mild and focal, that in C57BI/6 mice was more severe. The necrosis of hepatocytes was also observed in severely affected livers (Fig. 3d). Mild or moderate perivascular inflammation was scattered throughout the kidney, heart, and lung. Although splenitis was not detected, hyperplasia of white pulp was frequently observed in mice in IG (BALB/c: $6 / 6$, C57BI/6: 5/6). No significant changes were noted in the intestines, uterus, brain, or spinal column of mice in IG. In mice in CG, inflammation was not detected in systemic organs or tissues, and axonal degeneration of the sciatic nerve and white pulp hyperplasia of the spleen was also not observed. Extramedullary hematopoiesis was noted in mice in CG (BALB/c: 1/5, C57BI/6: 4/5) and IG (BALB/C: 6/6, C57BI/6: 4/6), and was more frequent in BALB/C mice in IG than in CG. In addition, the degrees of extramedullary hematopoiesis were more severe in BALB/C and C57BI/6 mice in IG than in those in CG.

At the time of necropsy, parasitemia was observed in 2 BALB/c mice and 5 C57BI/ 6 mice in IG. In mice in IG with parasitemia, parasites were detected extracellularly at the inflammatory foci of the heart (BALB/C: $0 / 2, \mathrm{C} 57 \mathrm{BI} / 6: 1 / 5)$, the perineurium and perineural connective tissue of the sciatic nerve (BALB/C: $2 / 2$, $\mathrm{C} 57 \mathrm{BI} / 6: 5 / 5)$, the vagina (BALB/C: $2 / 2, \mathrm{C} 57 \mathrm{BI} / 6: 5 / 5)$, and dermis and subcutaneous tissue (BALB/C: 1/1, C57BI/6: 2/2). Even in mice in IG without parasitemia, parasites were present in the heart (BALB/C: 2/4, C57BI/6: 0/1), perineurium and perineural connective tissue of the sciatic nerve (BALB/c: 3/4, $\mathrm{C} 57 \mathrm{BI} / 6: 0 / 1)$, the vagina (BALB/C: 0/4, $\mathrm{C} 57 \mathrm{BI} / 6: 1 / 1)$, and dermis and subcutaneous tissue (BALB/C: 1/4, C57BI/6: 1/1). With or without the detection of parasitemia at the time of necropsy, a large number of parasites were present in the perineural connective tissue of BALB/C and C57BI/6 mice in IG (Fig. 4a) and the dermis and subcutaneous tissue of the dorsal skin with alopecia and redness in C57BI/6 mice in IG (Fig. 4b). Parasites were not observed in any organs or tissues in mice in CG.

\section{Discussion}

T. equiperdum infects equids chronically and causes dourine. The clinical course of dourine is chronic, ranging from a few months to several years ${ }^{5,22}$. In contrast to other trypanosomes that are frequently detected in blood and lymph fluids, T. equiperdum is rarely detected in the blood of chronically infected horses $^{4,23,24}$. In experimental infection using mice, the majority of $T$. equiperdum strains did not infect mice or rapidly increased parasitemia if infection occurred, resulting in an acute course and death $8,10-12$. In the present study, 5/6 BALB/c (one mice died in an anesthesia accident) and 3/6 C57BI/6 mice in IG 
survived throughout the experimental period, and periodic parasitemia was also observed throughout the experimental period in IG of both mouse strains. Therefore, these results indicate that BALB/C and C57BI/6 mice were chronically infected with the T. equiperdum IVM-t2 strain. Parasites were observed histologically in the heart, perineurium, perineural connective tissue, vagina, dermis, or subcutaneous tissue of T. equiperdum IVM-t2 strain-infected mice with parasitemia at the time of necropsy. Even in mice with parasitemia levels below the detection limit at the time of necropsy, parasites were also detected in these organs and tissues. Therefore, the heart, perineurium, perineural connective tissue, vagina, dermis, and subcutaneous tissue may have tissue tropism for the T. equiperdum IVM-t2 strain.

In the present study, the survival rate was lower in $\mathrm{C} 57 \mathrm{BI} / 6$ mice than in BALB/c mice in IG. Inflammation in the liver, sciatic nerve, vagina, and skin was more severe in $\mathrm{C} 57 \mathrm{Bl} / 6$ mice than in BALB/c mice. These results indicated that $\mathrm{C} 57 \mathrm{BI} / 6$ mice were more susceptible to the $T$. equiperdum IVM-t2 strain than $\mathrm{BALB} / \mathrm{c}$ mice. This difference in susceptibility between BALB/C and C57BI/ 6 mice may be due to differences in the predominant $T$ lymphocyte subsets between these mouse strains. The predominant helper T cell in the blood and spleen of BALB/c mice is Th1 cells, while that in C57BI/ 6 mice is Th2 cells $^{16-19}$. According to previous studies on African trypanosomiasis using various mouse strains, C57BI/ 6 mice generally achieve a longer survival time than BALB/c mice ${ }^{3}$. An immunological study on African trypanosomiasis identified Th1 cells and their related cytokines as the main immune responses against parasites ${ }^{25-28}$. In the present study, $\mathrm{C} 57 \mathrm{BI} / 6$ mice had a shorter survival time than BALB/c mice. However, the relationship between infection with T. equiperdum and the immune response of hosts remains unknown. The primary immune response against parasites may differ between $T$. equiperdum and other African trypanosomes.

Clinical signs observed in dourine-affected horses include local edema in the genitalia and mammary glands, skin plaques, anemia, and neurological signs, such as paralysis of the hind limbs and facial muscles ${ }^{5}$. Although anemia was reported in a previous experimental infection with $T$. equiperdum strains using mice, no other clinical signs were observed ${ }^{11}, 12$. Since severe extramedullary hematopoiesis was detected in T. equiperdum IVM-t2 strain-infected BALB/c and C57BI/ 6 mice, mice in IG may have been anemic. Furthermore, redness and alopecia of the dorsal skin were observed in chronically infected C57BI/ 6 mice. The histopathological finding of skin plaques in dourine-affected horses, described as "trypanosomal sand", is characterized by the presence of parasites and severe inflammation in the dermis $^{29}$. In the present study, inflammation with the presence of parasites was observed in the dermis and subcutaneous tissue. The skin plaques of dourine has never been reproduced in experimental animals. The present study successfully reproduced "trypanosomal sand" lesions in C57BI/6 mice chronically infected with the T. equiperdum IVM-t2 strain.

A previous study on $T$. brucei using mice revealed that adipose tissue was a main extravascular parasite niche during its lifecycle ${ }^{30}$. To the best of our knowledge, the relationship between T. equiperdum and adipose tissue in dourine-affected horses has not yet been investigated. Parasites were detected in the dermis as well as in the subcutaneous adipose tissue of T. equiperdum IVM-t2 strain-infected mice by 
immunohistochemistry, and these results suggested that $T$. equiperdum may also parasitize adipose tissue as a parasite niche.

In the female reproductive organs of dourine-affected horses, inflammation was distributed in the epithelium, lamina propria, and tunica muscularis of the vagina and uterine submucosa ${ }^{6,8}$. A histopathological examination of the vagina and uterus of $\mathrm{BALB} / \mathrm{C}$ and $\mathrm{C} 57 \mathrm{BI} / 6$ mice infected with the $T$. equiperdum IVM-t2 strain revealed inflammation in the vaginal lamina propria and tunica muscularis. Significant lesions were not observed in the epithelium of the vagina. In the present study, mice were infected with $T$. equiperdum by an intraperitoneal injection, and parasites were distributed to the vagina via the bloodstream. On the other hand, T. equiperdum are transmitted during coitus in horses and cause vaginitis ${ }^{5}$. Differences in the distribution of inflammation in the vagina between dourine-affected horses and T. equiperdum IVM-t2 strain-infected mice may be due to the different routes of infection. Although $T$. equiperdum is transmitted during coitus in nature, the precise mechanism remains unclear ${ }^{5,24}$. Further experiments using T. equiperdum IVM-t2 strain-infected BALB/c and C57BI/6 mice, such as the evaluation of genital lesions in male mice and the demonstration of transmission by coitus, are needed to reveal the mechanism of $T$. equiperdum transmission.

Inflammation and the parasitism of numerous parasites were observed in the perineurium and surrounding connective tissue in $\mathrm{BALB} / \mathrm{c}$ and $\mathrm{C} 57 \mathrm{BI} / 6$ mice infected with the $T$. equiperdum IVM-t2 strain. There were no inflammatory cells within the nerve bundles. In peripheral neuritis in dourine-affected horses, lymphocytes, plasma cells, and macrophages infiltrated the epineurium, perineurium, and within nerve bundles ${ }^{6,7}$. Parasites have not been histologically detected in lesions ${ }^{7}$. Therefore, the nature and distribution of inflammation in peripheral nerves differed between horses and mice. Peripheral neuritis in some dourine-affected horses involved axonal swelling and fragmentation, and axonal degeneration was the cause of neurological signs ${ }^{7}$. Although mild axonal degeneration was also observed in some infected mice, they did not exhibit neurological signs. Therefore, mice infected with the T. equiperdum IVM-t2 strain may not reflect the pathophysiology of dourine-associated peripheral neuritis in the present study.

In conclusion, we herein established a T. equiperdum chronically infected mouse model using the $T$. equiperdum strain adapted to in vitro conditions. These mouse models exhibited similar clinical signs and histopathological lesions to those in dourine-affected horses. Therefore, these mouse models will make significant contributions to pathological, immunological, and parasitological in vivo research to elucidate the mechanisms underlying the disease process and the host-protozoa relationship in dourine.

\section{Materials And Methods}

\section{Ethical approvement}

The present experiments were approved by the Obihiro University of Agriculture and Veterinary Medicine Committee for Experiments Using Animals (approved number 19-23). All methods were carried out in 
accordance with relevant guidelines and regulations in Japan. We carried out the experiments in compliance with the ARRIVE guidelines.

\section{T. equiperdum strain}

The T. equiperdum strain used in the present study was the IVM-t2 strain (T. equiperdum isolated at the Institute of Veterinary Medicine from a Töv aimag dourine horse no. 2). This strain was isolated from the genital mucosa of a dourine-affected horse in Mongolia and adapted to soft agarose media using the methods established by Suganuma et al. ${ }^{14}$.

\section{Experimental design}

Eleven 6-week-old female BALB/c and C57BI/6 mice obtained from CLEA Japan Inc. (Tokyo, Japan) were used for experimental infection. Six mice of each mouse strain were intraperitoneally injected with $1 \times 10^{6}$ T. equiperdum IVM-t2 strain parasites. As the control group, 5 mice of each mouse strain were intraperitoneally injected with sterilized phosphate-buffered saline. The number of parasites in blood was counted using a cell counting chamber and blood samples taken from a tail vein 3 times a week. All mice were euthanized at $60 \mathrm{dpi}$ by anesthesia with isoflurane and blood drawing from the heart. The liver, spleen, kidney, heart, lung, intestine, uterus, vagina, brain, spinal column including the vertebrae and spinal cord, and sciatic nerve were collected and fixed in $10 \%$ neutral buffered formalin. Although the dorsal skin was collected from mice that survived for 60 days, it was not collected from those that died in the early stage of experimental infection.

\section{Histopathological examination}

Formalin-fixed samples were routinely processed and embedded in paraffin. Paraffin sections were stained with hematoxylin and eosin $(\mathrm{HE})$ and subjected to a histopathological examination. Fixed spinal columns were washed with tap water for one hour, and placed in Anna Morse solution (decalcification solution made of sodium citrate and formic acid) for 48 hours. Decalcified spines were washed with tap water for 12 hours, and sectioned at the seventh cervical and third lumber vertebra for histopathological examination. The degree of inflammation in each section of systemic organs and tissues was evaluated using the following criteria: - = no inflammation, $+=$ mild and focal inflammation, $++=$ moderate inflammation, +++ = severe and diffuse inflammation. The degrees of extramedullary hematopoiesis and hyperplasia of white pulp in the spleen and axonal degeneration in the sciatic nerve were examined. Selected sections of the sciatic nerve were stained with Luxol fast blue (LFB)-HE stain to evaluate axonal degeneration.

\section{Immunohistochemistry}

An immunohistochemical examination was performed to evaluate the distribution of parasites in each organ and tissue. Sections were deparaffinized by xylene and hydrated in a series of graded ethanol. Citrate buffer was used for antigen retrieval at $97^{\circ} \mathrm{C}$ for $15 \mathrm{~min}$. Non-specific endogenous peroxidase was 
blocked with $0.3 \% \mathrm{H}_{2} \mathrm{O}_{2}$ at room temperature for $10 \mathrm{~min}$. Sections were incubated with anti- $T$. equiperdum rabbit antisera $\left(1: 400, \mathrm{~K}\right.$. Suganuma) as the primary antibody at $4^{\circ} \mathrm{C}$ overnight. MAX-PO polymer reagent (Nichirei, Bioscience, Tokyo, Japan) was used as the secondary antibody at room temperature for $30 \mathrm{~min}$. Labeling was visualized by 3,3'-diaminobenzidine, and sections were counterstained by Mayer's hematoxylin.

\section{Declarations}

\section{Acknowledgments}

The present study was supported by a cooperative research grant (2019-joint-15) from the National Research Center for Protozoan Diseases, Obihiro University of Agriculture and Veterinary Medicine.

\section{Competing interests}

The authors declare no competing interests.

\section{Data availability}

All data generated during this study are included in this published article.

\section{Author contribution statement}

$\mathrm{YT}, \mathrm{KS}$, and $\mathrm{YK}$ performed animal experiments. $\mathrm{YT}, \mathrm{KW}$, and $\mathrm{YK}$ performed histopathological examinations. YT and YK wrote the main manuscript and prepared all figures and tables. All authors reviewed the manuscript.

\section{References}

1. Büscher, P., Cecchi, G., Jamonneau, V., Priotto, G. Human African trypanosomiasis. 390, 2397-2409 (2017).

2. Giordani, F. et al. The animal trypanosomiases and their chemotherapy: a review. 143, 1862-1889 (2016).

3. Antoine-Moussiaux, N., Magez, S. \& Desmecht, D. Contributions of experimental mouse models to the understanding African trypanosomiasis. Parasitol. 24, 411-418 (2008).

4. Gizaw, Y., Megersa, M. \& Fayera, T. Dourine: a neglected disease of equids. Anim. Health. Prod. 49, 887-897 (2017).

5. Dourine in Manual of Diagnostic Tests and Vaccines for Terrestrial Animals (mammals, birds and bees) 8th 1260-1269 (OIE 2018). 
6. Yasine, A. et al. Histopathological lesions in reproductive organs, distal spinal cord and peripheral nerves of horses naturally infected with Trypanosoma equiperdum. BMC Vet. Rec. 15, 175; 10.1186/s12917-019-1916-7 (2019).

7. Mungun-Ochir, B. et al. Polyradiculoneuropathy in dourine-affected horses. Disord. 29, 437-443 (2019).

8. Pascucci, I. et al. Diagnosis of dourine in outbreaks in Italy. Parasitol. 193, 30-38 (2013).

9. Tanaka, Y. et al. Immunohistochemical phenotyping of macrophages and T lymphocytes infiltrating in peripheral nerve lesions of dourine-affected horses. Vet. Med. Sci. 82, 1502-1505(2020).

10. Gillingwater, K. In vitro and in vivo efficacy of diamidines against Trypanosoma equiperdum Parasitology. 145, 953-960 (2018).

11. Hagos, A. et al. Efficacy of Cymelarsan and Diminasan against Trypanosoma equiperdum infections in mice and horses. Parasitol. 171, 200-206 (2010).

12. Perrone, T. et al. Comparison of infectivity and virulence of clones of Trypanosoma evansi and Ttrypanosoma equiperdum Venezuelan strains in mice. Parasitol. 253, 60-64 (2018).

13. Perrone, T. M., Gonzatti, M. I., Villamizar, G., Escalante, A. \& Aso, P. M. Molecular profiles of Venezuelan isolates of Trypanosoma sp. by random amplified polymorphic DNA method. Parasitol. $161,194-200$ (2009).

14. Suganuma, K. et al. Isolation, cultivation and molecular characterization of a new Trypanosoma equiperdum strain in Mongolia. Vectors. 9, 481; 10.1186/s13071-016-1755-3 (2016).

15. Tizard, I. R. Helper T cells and their response to antigen in Veterinary Immunology 9th (ed. Tizard, I. R.) 137-149 (Elsevier, 2013)

16. Cooley, L. F. et al. Increased B Cell ADAM10 in allergic patients and Th2 prone mice. PLOS ONE. 10, e0124331; 1371/journal.pone.0124331 (2015).

17. Nishimura, T. et al. Involvement of IL-4-producing Vbeta8.2+ CD4+ CD62L-CD45RB- T cells in non$\mathrm{MHC}$ gene-controlled predisposition toward skewing into T helper type-2 immunity in BALB/c mice. Immunol. 158, 5698-5706 (1997).

18. Pinchuk, L. M. \& Filipov, N. M. Differential effects of age on circulating and splenic leukocyte populations in C57BL/ 6 and BALB/c male mice. Ageing. 5, 1; :10.1186/1742-4933-5-1 (2008).

19. Yamaguchi, A., Togashi, Y., Koda, T. \& Nishimura, T. Development of DNA array filter useful for the analysis of Th1-Th2 balance. J. Clin. Immunol. 28, 86-91 (2005).

20. Cheers, C., Mckenzie, L. F. C., Pavlov, H., Waid, C. \& York, J. Resistance and susceptibility of mice to bacterial infection: course of listeriosis in resistant or susceptible mice. Immun. 19, 763-770 (1978).

21. Henderson, K. S. et al. A Comparison of Mouse Parvovirus 1 Infection in BALB/C and C57BL/6 Mice: Susceptibility, Replication, Shedding, and Seroconversion. Med. 65, 5-14 (2015).

22. Vulpiani, M. P. et al. Reemergence of dourine in Italy; clinical cases in some positive horses. Equine Vet. Sci. 33, 468-474 (2013). 
23. Brun, R., Hecker, H. \& Lun, Z. R. Trypanosoma evansi and equiperdum: distribution, biology, treatment and phylogenetic relationship (a review). Vet. Parasitol. 79, 95-107 (1998).

24. Schlafer, D. H. \& Foster, R. A. Female genital system in Jubb, Kennedy, and Palmer's Pathology of Domestic Animals Volume 3 6th (ed. Maxie, M. G.) 358-464 (Elsevier, 2016).

25. Bakari, S. M. et al. Serum biochemical parameters and cytokine profiles associated with natural African trypanosome infections in cattle. Vectors. 10,312; 10.1186/s13071-017-2255-9 (2017).

26. Hertz, C. J., Filutowicz, H. \& Mansfield, J. M. Resistance to the African trypanosomes is IFN-gamma dependent. Immunol. 161, 6775-6783 (1998).

27. O'Gorman, G. M. et al. Cytokine mRNA profiling of peripheral blood mononuclear cells from trypanotolerant and trypanosusceptible cattle infected with Trypanosoma congolense. Genomics. 28, 53-61 (2006).

28. Schleifer, K. W., Filutowicz, H., Schopf, L. R. \& Mansfield, J. M. Characterization of T helper cell responses to the trypanosome variant surface glycoprotein. Immunol. 150, 2910-2919 (1993).

29. Scacchia, M. et al. A clinical case of dourine in an outbreak in Italy. Ital. 47, 473-475 (2011).

30. Trindade, S. et al. Trypanosoma brucei parasites occupy and functionally adapt to the adipose tissue in mice. Cell Host Microbe. 19, 837-848 (2016).

\section{Table}

Due to technical limitations, table $1 \mathrm{xlsx}$ is only available as a download in the Supplemental Files section.

\section{Figures}




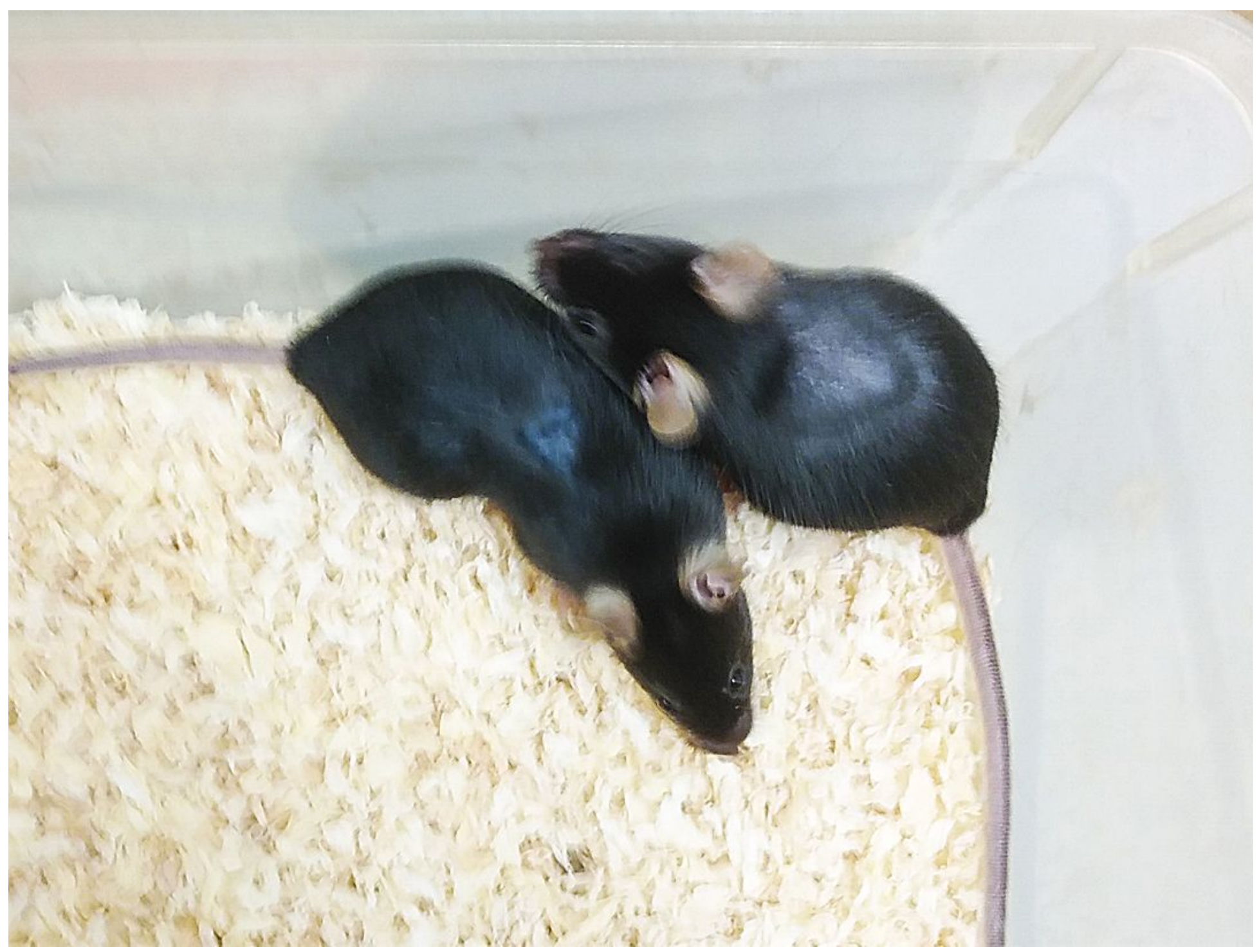

Figure 1

C57BI/6 mice in the infected group. Alopecia and redness are observed on the dorsal skin. 


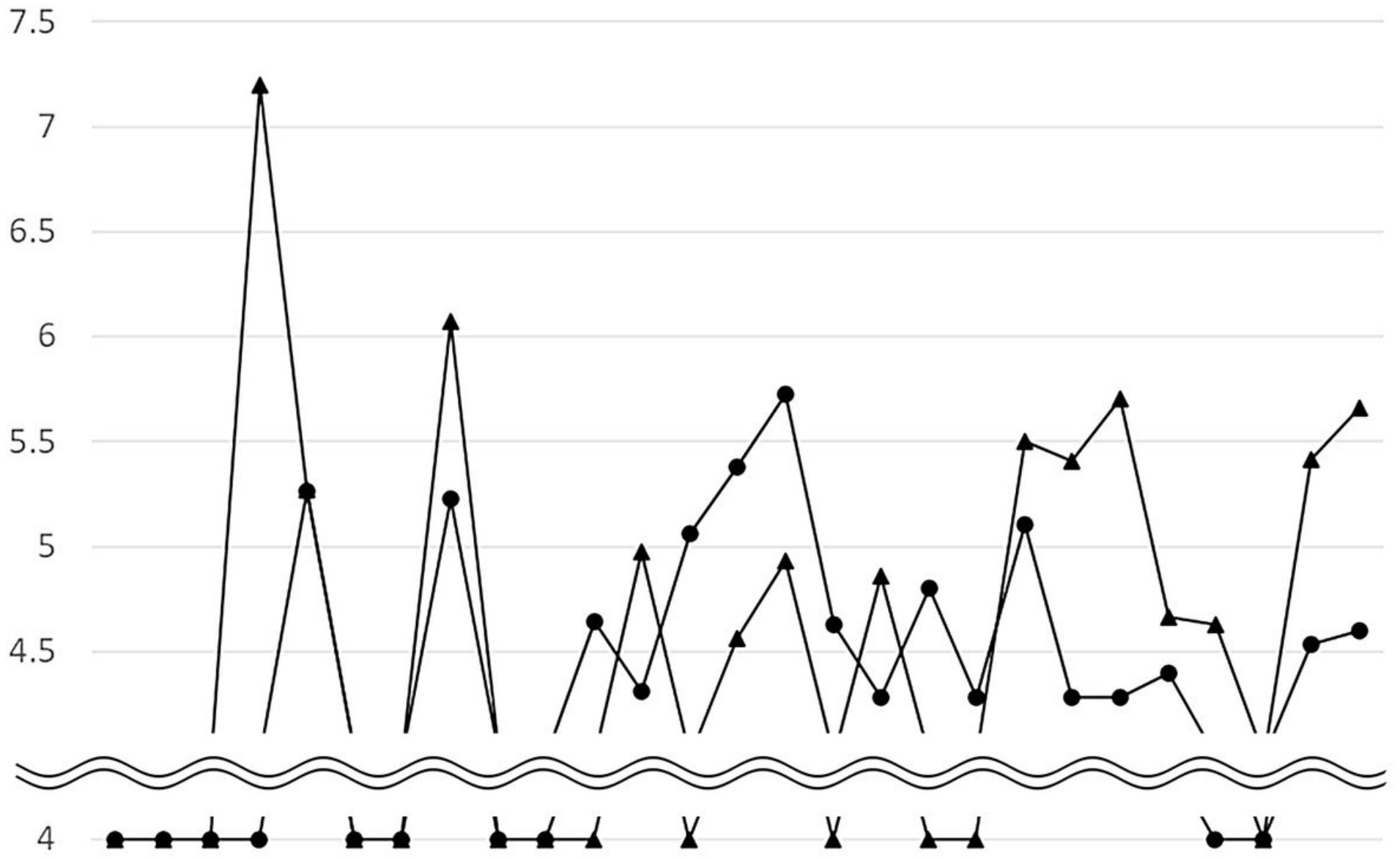

13581012151719222426293133363840434547505254575960 $\rightarrow \mathrm{BALB} / \mathrm{C} \longrightarrow \mathrm{C} 57 \mathrm{BI} / 6$

Figure 2

Average parasitemia in each mouse strain in the infected group $(\log 10$ parasites $/ \mathrm{mL}$, limit of detection is $1 \times 104$ parasites $/ \mathrm{mL}$ ). Periodic parasitemia is observed in both mouse strains. 

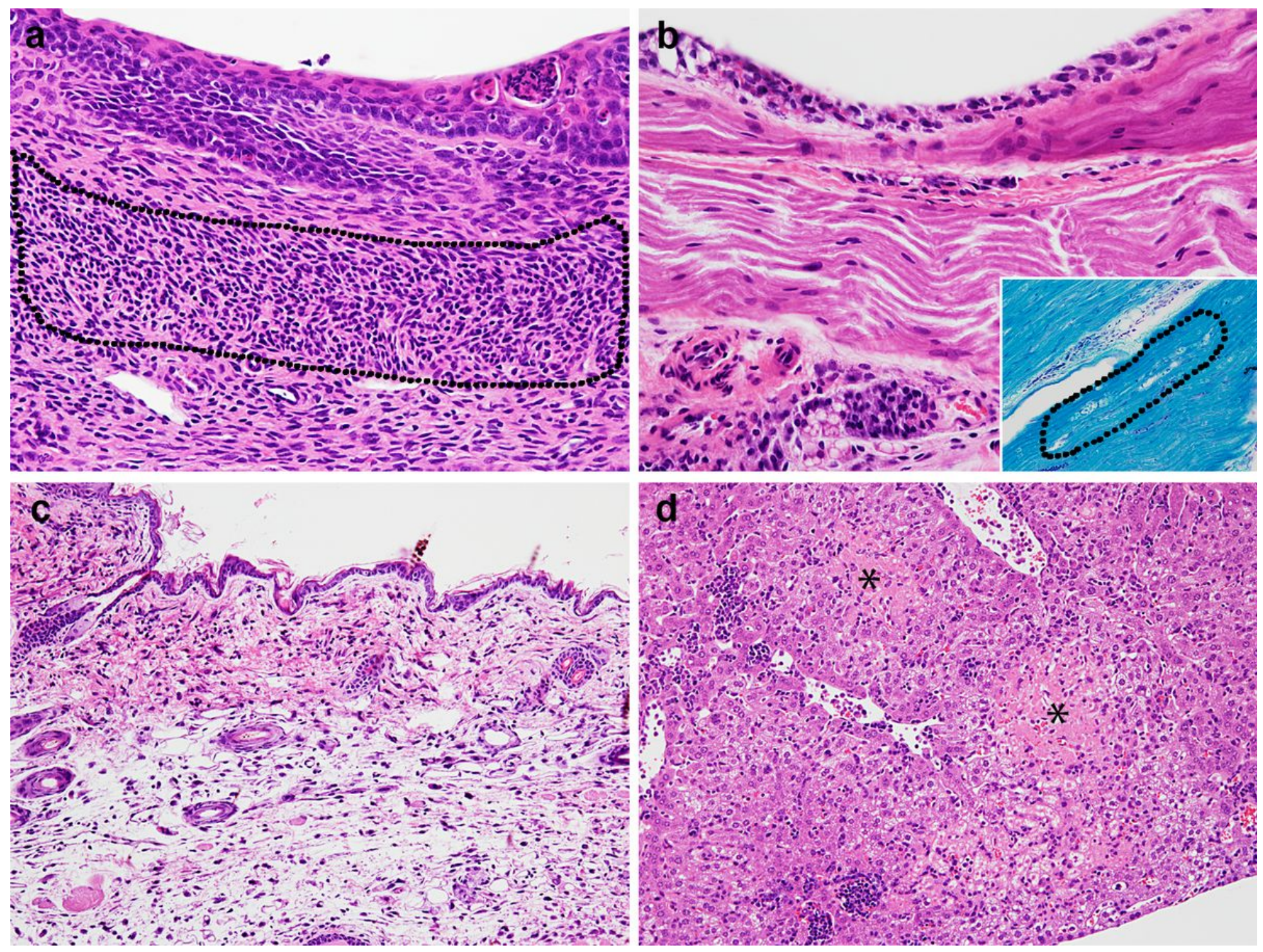

\section{Figure 3}

a) Vagina of a C57BI/6 mouse in the infected group (IG). HE stain. Diffuse inflammation is observed in the lamina propria and tunica muscularis of the vagina (dotted line). b) The sciatic nerve of a BALB/c mouse in IG. HE stain. Although inflammatory cells are detected in the perineurium and surrounding connective tissues, they are not observed within the nerve bundles. (In set: Sciatic nerve. BALB/c mouse in IG. LFB-HE stain. Several axons are degenerated (dot line)) c) Skin of a C57BI/6 mouse in IG. HE stain. Alopecia and redness are grossly observed in the dorsal skin, and lymphocytes diffusely infiltrated the dermis and subcutaneous tissue. Edema is also observed. The number of follicles and glands are small. d) Liver of a C57BI/6 mouse in IG. HE stain. Multifocal perivascular inflammation and the necrosis of hepatocytes (asterisk) are observed. 

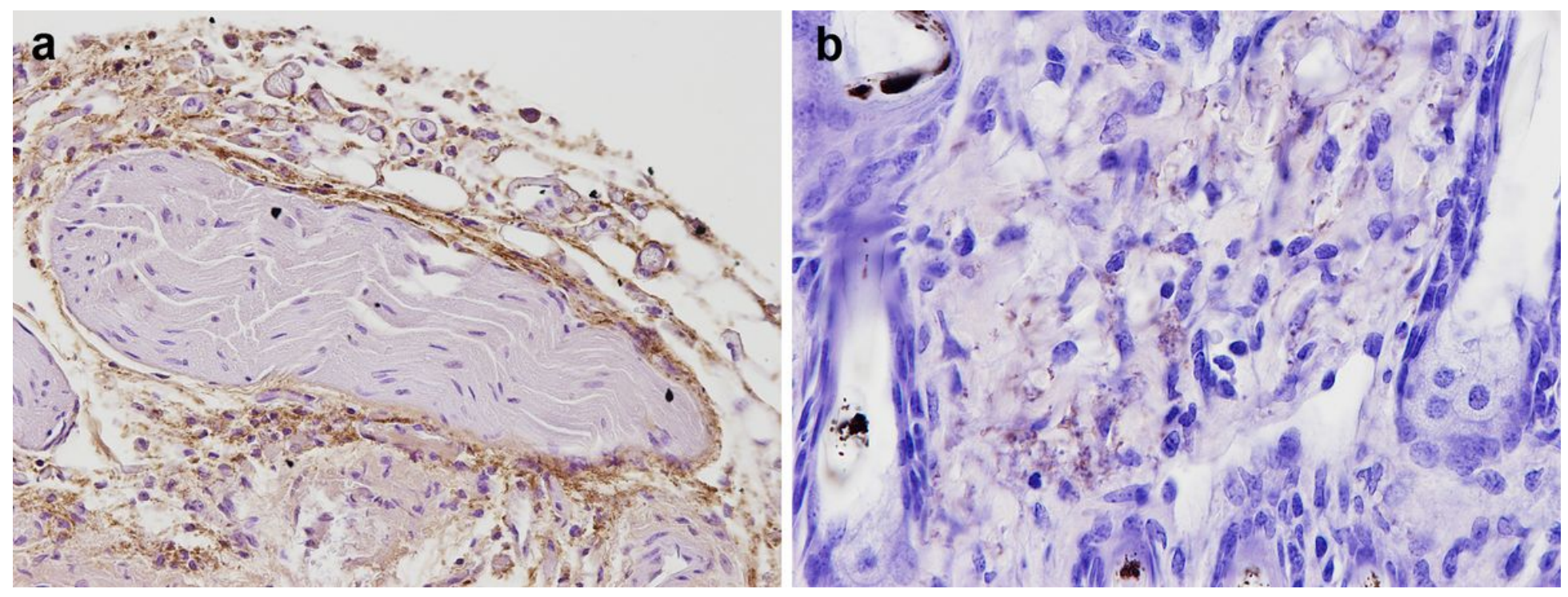

\section{Figure 4}

a) Sciatic nerve of a C57BI/6 mouse in the infected group (IG). Immunohistochemistry with an anti-T. equiperdum antibody. Numerous parasites are detected in the perineurium and perineural connective tissue, but not within nerve bundles. b) Skin of a C57BI/6 mouse in IG. Immunohistochemistry with an anti-T. equiperdum antibody. Numerous parasites are observed in the dermis and subcutaneous tissue of the dorsal skin with alopecia and redness.

\section{Supplementary Files}

This is a list of supplementary files associated with this preprint. Click to download.

- Table1.xlsx 